\title{
An Overview on the Continuous Severe Plastic Deformation Methods
}

\author{
Ghader Faraji* and Hesam Torabzadeh \\ School of Mechanical Engineering, College of Engineering, University of Tehran, Tehran 11155-4563, Iran
}

Severe Plastic Deformation (SPD) processes have been extensively investigated in the last 30 years to facilitate the production processes of nanostructured (NS) or ultrafine-grained (UFG) materials with unique properties. However, the majority of the efforts were limited on the laboratory-scale investigations not to be able to overcome the demands for industrial scale applications. Researchers have tried to introduce effective industrial methods for processing large and long UFG/NG materials. In this review, all industrial processes especially continuous SPD methods which are more suitable for mass production are categorized and explained. Furthermore, the factors influencing the process efficiency were presented to give a vision to the researchers who want to step in this scientific field. Finally, the industrial processes were compared regarding final microstructure and properties. [doi:10.2320/matertrans.MF201905]

(Received January 16, 2019; Accepted April 15, 2019; Published June 25, 2019)

Keywords: sever plastic deformation, continuous, sample size, microstructure, properties

\section{Introduction}

Grain refinement results in reducing the grain size to below $100 \mathrm{~nm}$ called nanostructured (NS) or submicron level called ultrafine-grained (UFG) and causes a significant increase in the strength, fatigue resistance, superplasticity, wear resistance, etc. that make more useful materials for different industries. ${ }^{1-3)}$ Severe plastic deformation (SPD) processes are attributed to those of metal forming in which the high shear deformation is imposed on the material at the high hydrostatic pressure presence for producing UFG or NS materials.

The SPD technology has been started with the seminal work by P.W. Bridgman who developed the scientific core and techniques for processing of materials through a combination of large shear deformation under high hydrostatic pressure that resulted in the Nobel Prize in Physics in 1946 for him. ${ }^{4-7)}$ Another major attempt on SPD processing development may be related to the researches of Prof. Segal and his colleagues, performed in the 1980s. They succeed to present the most popular SPD method so-called equalchannel angular pressing (ECAP) for the first time. ${ }^{8)}$ The microstructural evaluations of the SPD approach were first accomplished by Professor R.Z. Valiev and his colleagues in the 1980s. ${ }^{9)}$

The science and technology of SPD processing have been widely developed during the past three decades by many scientists and researchers in different countries tried to introduce optimized, low-cost and useful methods. However, SPD methods would be effective when not only be investigated in laboratory scales but also make the possibility of producing the UFG and NS samples in industrial applications. Scientists are trying to extract the commercial opportunities from SPD approach so that they will be able to achieve promising practical usage.

After three decades of research in this field, it is time for the final step for the commercialization of SPD processed materials. In this research, a comprehensive review was done for different SPD processes presented by researchers as industrial methods which have the potential of manufacturing the large-scale samples. Here, all the methods were

*Corresponding author, E-mail: ghfaraji@ut.ac.ir categorized into three classes based on the nature of deformation. After the explanation of every method in details, the methods were compared regarding sample size, microstructure and mechanical properties of final products. So, the content of this article can help researchers to attain the exact vision of industrial SPD methods.

Here, the processes are categorized into three main groups; continuous, semi-continuous, discontinuous. The semicontinuous operations are attributed to those by which can process large-scale UFG or NS products, but in the continuous methods, the sample is almost infinite. As a criterion, in continuous processes, both ends of the sample are stress-free while in discontinuous methods only one side or none of them are stress-free.

As reviewed recently, there are many discontinuous SPD methods $7,10,11)$ could be categorized in three groups based on their suitability for bulk, sheet, and tubular samples. Some of discontinuous processes suitable for bulk samples consist but not limited to high pressure torsion (HPT) ${ }^{12)}$ Multidirectional forging, ${ }^{13)}$ High-Pressure Torsion Extrusion (HPTE), ${ }^{14)}$ ECAP, ${ }^{8,15)}$ Torsional-ECAP, ${ }^{16}$ Multi-pass ECAP, ${ }^{17)}$ ECAP with parallel channels, $\left.{ }^{18}\right)$ Rotary-die ECAP, ${ }^{19)}$ Side-extrusion, ${ }^{20)}$ Expansion ECAP, ${ }^{21)}$ Channel angular pressing with converging billets, ${ }^{22)}$ Equal Channel Forward Extrusion (ECFE), ${ }^{23)} \mathrm{C}$-shape equal channel reciprocating extrusion, ${ }^{24)}$ Torsion Extrusion (TE), ${ }^{25)}$ Cyclic Extrusion-Compression, ${ }^{26,27)}$ Cyclic Expansion-Extrusion, ${ }^{28)}$ Accumulated Extrusion (AE), Multiple Direct Extrusion, ${ }^{29)}$ Elliptical Cross-section Spiral Equal Channel Extrusion (ECSEE), ${ }^{30)}$ Twist Extrusion, ${ }^{31,32)}$ Planar Twist Extrusion (PTE), ${ }^{33)}$ Pure Shear Extrusion (PSE), ${ }^{34)}$ Axi-symmetric Forward Spiral Extrusion, ${ }^{35)}$ Accumulative Back Extrusion, ${ }^{36)}$ Half Channel Angular Extrusion, ${ }^{37)}$ Cyclic Forward-Backward Extrusion (CFBE) ${ }^{38)}$ Multi-Axial Incremental Forging and Shearing, ${ }^{39)}$ Repetitive Upsetting and Extrusion (RUE), ${ }^{40,41)}$ Repetitive Upsetting (RU), ${ }^{42}$ Accumulative Channel-die Compression Bonding (ACCB), ${ }^{43)}$ Cylinder Covered Compression, ${ }^{44)}$ Twist Channel Angular Pressing (TCAP), ${ }^{45}$ Twist channel multi-angular pressing (TCMAP) ${ }^{46)}$ and Cyclic Extrusion Compression Angular Pressing (CECAP). ${ }^{47)}$ Discontinuous SPD processes suitable for deforming sheet and tube samples consist but not limited to Cone-Cone Method, ${ }^{48)}$ Constrained 
Groove Pressing (CGP), ${ }^{49)}$ Interface sheet CGP, ${ }^{50}$ Rubber Pad-Constrained Groove Pressing (RP-CGP), ${ }^{51)}$ Friction Stir Processing, ${ }^{52)}$ high-pressure tube twisting, ${ }^{53)}$ accumulative spin-bonding, ${ }^{54)}$ tubular channel angular pressing, ${ }^{55,56)}$ parallel TCAP, ${ }^{57,58)}$ high-pressure tube shearing (THPS), ${ }^{59)}$ cyclic flaring and sinking, ${ }^{60)}$ rubber pad tube straining, ${ }^{61)}$ and friction stir back extrusion (FSBE). ${ }^{62}$ )

Semi-continuous methods are similar to discontinuous methods except that the stresses on sides are almost smaller. Also, the processable sample length in semi-continuous methods is larger than that from discontinuous processes. For example, the ECAP process is discontinuous in which the material at the inlet channel experience large compressive stresses while ARB is continuous where both sides of the sample are stress-free.

\section{Semi-Continuous SPD Methods}

\subsection{Integrated extrusion and equal channel angular pressing (IE-ECAP)}

There are two main obstacles for using equal channel angular pressing (ECAP) process for industrial fabrication of UFG/NG samples. First one is its low productivity and the second is the limited length of the extruded billet. The latter is because of the high possibility of punch yielding/buckling as a result of the high processing load in the case of long samples. As is realized, the large amount of deformation load in pressing based processes is consumed to overcome the friction forces. ${ }^{63,64)}$ Orlov et al. demonstrated the feasibility of upscaling of SPD technique by an integrated die combining conventional extrusion and ECAP as an integrated processing step. ${ }^{65}$ )

As shown schematically in Fig. 1, the sample is first extruded via a conical section and subsequently via two parallel channels in which the material experiences two angular deformations. The angle, $\varphi$, at which they intersect the connecting channel and the distance, $\mathrm{K}$, between the axes of the two parallel channels are two main factors which affect the microstructure evaluation. ${ }^{65)}$

Similarly, Abdolvand et al. presented a similar combined process for tubular components. ${ }^{63,66)}$ These processes may increase the efficiency of the process by increasing the length of the final sample with reduced cross section. However, the sample length at the entrance is dramatically decreased in comparison with ECAP. Also, increasing the hydrostatic compressive stress may predict for the process leading to better mechanical properties. ${ }^{67)}$ It may be concluded that the

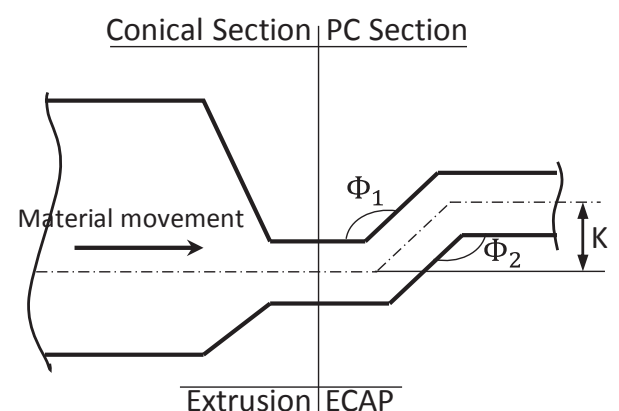

Fig. 1 The integrated ECAP and extrusion method. ${ }^{65)}$ above processes are not continuous though it could be classified as industrial approaches.

\subsection{Incremental ECAP (IECAP)}

As mentioned, the more the length of the sample increases, the more friction is created, and the deformation load increases. Therefore, the possibility of punch yielding/ buckling raises in the ECAP process. Incremental ECAP was developed for the reduction of deformation forces by secluding feeding and plastic deformation stages from each other. $^{68,69)}$ The schematic of IECAP process is shown in Fig. 2. The holder and fixed die create the input channel while the moving punch and the fixed die establish the output channel. The moving punch applies the deformation by actuating cyclically with an appropriate angle to the extrusion direction. Oscillations of the moving punch along the specified direction play two roles of feeding and shear deformation. As soon as the moving punch contacts the sample, it deforms plastically at the corner shown as a "shaded" zone in Fig. 2. This operation is continuously performed, and sequential shear zones overlap leading to a uniform distribution of plastic strain through the specimen. The key point is the separation of the die and sample sequentially results in the elimination of the friction force enabling the processing of infinite samples continuously. ${ }^{70,71)}$

A T-shaped billet version of IECAP process presented in 2008 is illustrated in Fig. 3. ${ }^{70)}$ According to this configuration, two shear deformation zones are established with feeding the material and oscillation of moving punch. This

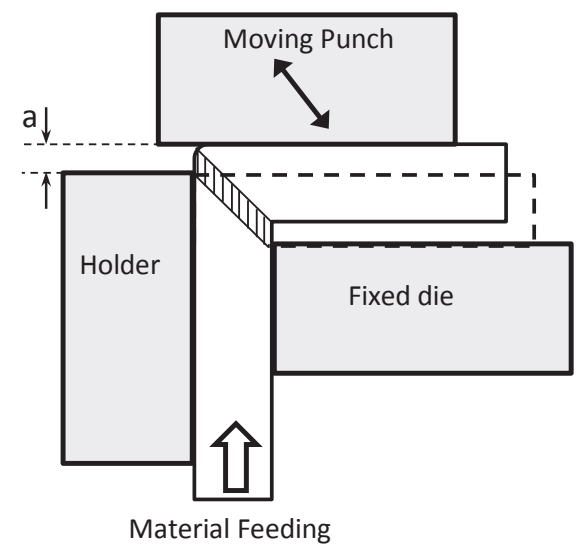

Fig. 2 Schematic illustration of IECAP. ${ }^{68,69)}$

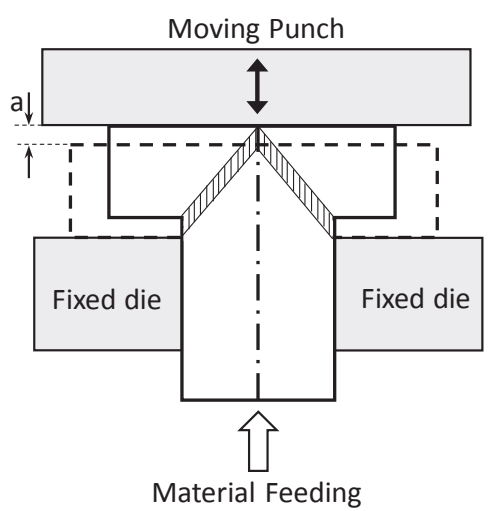

Fig. 3 Schematics of double billet IECAP. ${ }^{70)}$ 
could increase the efficiency of the process and also increase the process force compared to the IECAP method. ${ }^{70)}$ However, it seems the lower hydrostatic pressure on the sample compared to conventional ECAP may sacrifice the final mechanical properties.

\subsection{Porthole-equal channel angular pressing (P-ECAP)}

To overcome the main challenge in SPD methods which is the production of large components, ${ }^{72}$ the combination of conventional and SPD methods was used to develop Porthole-Equal Channel Angular Pressing (P-ECAP) herewith four portholes as a combination of extrusion and quadchannel ECAP to produce UFG long tubes including fourseam weld lines. ${ }^{73}$ ) Figure 4 depicts the P-ECAP method schematically. This procedure is similar to the conventional porthole extrusion except that the material experiences angular shear deformation at the exit channel. ${ }^{74}$ )

Like conventional porthole extrusion, if the die not to be designed properly, the material cannot be joined correctly at the seam lines. The P-ECAP could manufacture a UFG tube with a diameter larger than the initial billet, unlike the conventional porthole extrusion. So, the processing load is less compared to that for the conventional extrusion because of the decrease in the dimension of initial billet. ${ }^{73)}$

\subsection{Repetitive forging (RF) using inclined punches}

Repetitive forging using inclined punch developed by Faraji et al. in 2013 for producing UFG materials with square cross-section. ${ }^{75}$ In this process, the sample with a square cross-section is gradually deformed to parallelogram by forging between two lower and upper angular punches. Then, it gets back its original cross section by forging between flat punches. Recently, Zhilyaev et al. presented an almost similar process under continuous closed die forging (CCDF) name. ${ }^{76)}$ The schematic illustration of CCDF is shown in Fig. 5. At first, a rod is placed between two upper and lower dies. In the first pass, a load is applied to the dies to convert

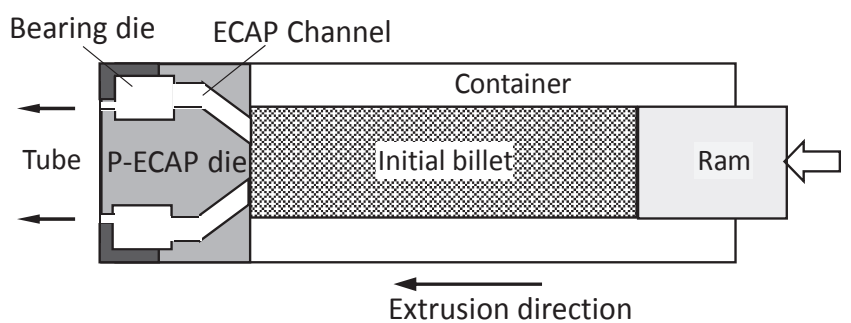

Fig. 4 Longitudinal section design of P-ECAP process. ${ }^{73)}$

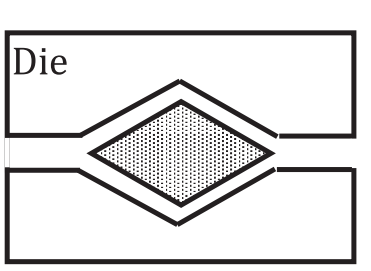

First Step

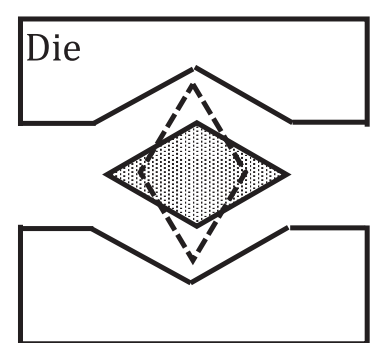

Second Step
Fig. 5 Schematic of continuous closed die forging (CCDF). ${ }^{76)}$ the cross-section of the sample to the rhomboidal one. Then the dies are opened, and the sample is turned $90^{\circ}$ to repeat the operation in the second pass. The process can be done in repetitive cycles to enhance a high plastic deformation. Though this method could process the samples longer than that in conventional ECAP, it still suffers from sample length limitation. Besides, because of the free deformation at the outer surface of the sample, it limits the workability of the material. So, the final applicable strain before cracking is limited and the minimum achievable grain size will increases. Considering the Hall-Petch relationship, final mechanical properties will not be better than conventional ECAP in which the sample is processed at a constrained status.

\subsection{Hydrostatic cyclic expansion extrusion (HCEE)}

The most important weakness in pressing-based methods is the high compression load and increasing the possibility of punch yielding/buckling leading to in the limitation of sample length/diameter. To reduce the deformation load, the friction force which is almost more than $80 \%$ of the total load in most SPD methods should be minimized. Hydrostatic based processes which eliminate friction by using thick fluid layer at the contacts seem to be very promising. Hydrostatic ECAP process was first investigated by Spuskanyuk et al. ${ }^{77)}$ Also, hydrostatic extrusion was also considered as a metal forming process for producing UFG/NG metals with exceptional mechanical properties. It was shown that it can even process hard to deform materials. ${ }^{78)}$

Very recently, Samadpour et al. ${ }^{79)}$ introduced an efficient technique in which the fluid pressure is used to remove frictional force and the material is deformed by hydraulic pressure. ${ }^{80)}$ This technique can be a promising step to design a frictionless process making possible the producing UFG large samples while applying relatively higher hydrostatic stresses.

A schematic of HCEE process based on Cyclic Expansion Extrusion $(\mathrm{CEE})^{81)}$ is shown in Fig. 6. As is clear, hydraulic fluid is cast between the sample and die container. While the fluid container is completely sealed and a bottom punch is placed, a movable punch is pressed so that the sample is pushed into the expansion zone. Because of the presence of the bottom punch, the billet is expanded to fill the die cavity. Then the bottom punch is removed, and the entire sample is passed from the expansion zone to apply a constant strain to throughout of sample length. Then, in order to start the second pass, the die is rotated $180^{\circ}$ and the processing will be performed as what was done before as shown in Fig. 8(b). However, HCEE counterpart suitable for processing of long UFG/NG tubular components with exceptional strength and ductility named HTCEE was patented by Faraji and Motallebi very recently. ${ }^{82)}$

\subsection{Single-task incremental high pressure torsion (SIHPT)}

Another step for the industrialization of HPT process was done by Hohenwarter in 2015 by the development of Incremental HPT. ${ }^{83)}$ Then, an incremental HPT process called SIHPT was developed for increasing the sample size which is the main disadvantageous of common HPT method. The different stages of the SIHPT process were shown in Fig. 7. 


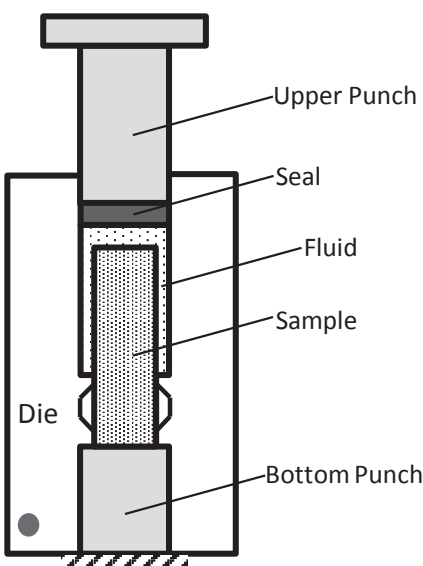

(a)

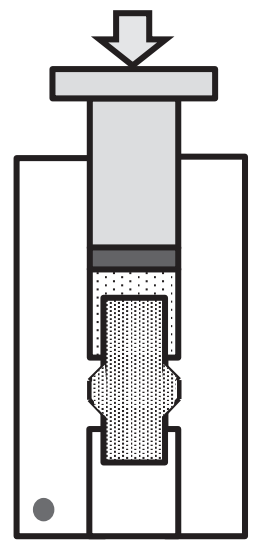

(c)

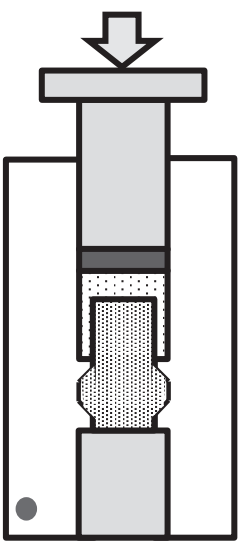

(b)

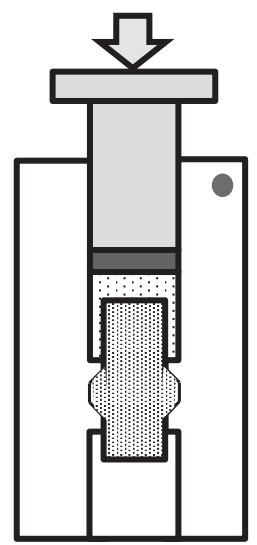

(d)
Fig. 6 First cycle of the HCEE process (a) first stage, (b) expansion stage. $^{79)}$
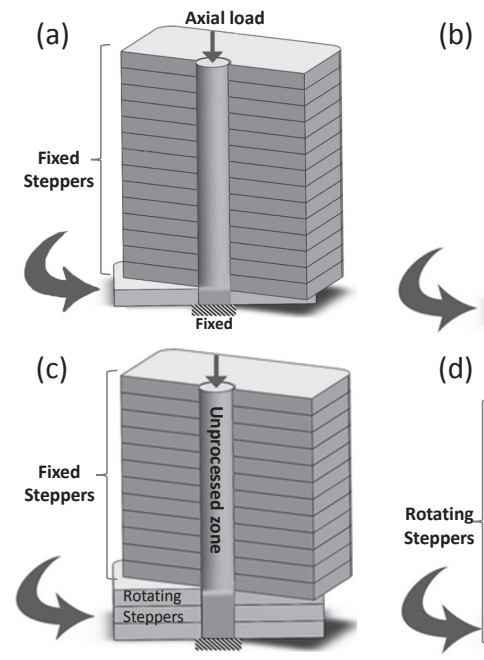

(d)
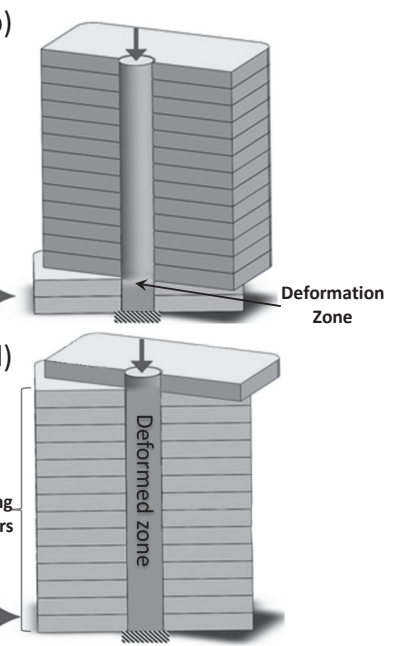

Fig. 7 Schematic of the SIHPT method done in different steps. $\left.{ }^{84}\right)$

Each part of the die is named stepper, and stepper's thickness defines the deformation area at each step. There is a hole in the center of steppers where a long rod with the circular cross-section is inserted. Because of the higher sample length, different zones of it are deformed step by step. The processing begins at the bottom of the sample and finishes at the top. ${ }^{84)}$ Though this procedure could increase the

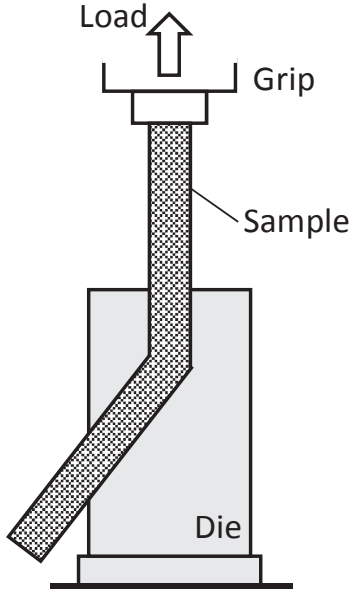

Fig. 8 Scheme of continuous ECAD process. ${ }^{29)}$

maximum processable length of the specimens, it is still not continuous.

\subsection{Equal-channel angular drawing (ECAD)}

In this process, the sample is pulled through the ECAE die with two intersecting channels at an angle of $\sim 135^{\circ}$ as shown in Fig. $8{ }^{85,86)}$ Drawing operation would decrease the required force by reducing the friction at the interface of the sample and die at the entrance channel. Besides, tensile stress at drawing based processes offers several problems including low hydrostatic pressure, initiation, and propagation of cracks/defects, low mechanical properties, and larger saturated grain sizes. ECAD process is potentially suitable for continuous SPD processing of UFG metals, but subsequent calculations and experiments revealed that it comprises a cross-sectional area reduction of the workpiece by more than $15 \%$. Therefore, it cannot be effectively utilized for industrial production of UFG/NG metallic materials. ${ }^{87,88)}$ In the ECAD process, the sample does not fill the dies completely that it causes to create flow instability of the sample and form the corner gap as a result of low hydrostatic pressure. ${ }^{89)}$ In addition, the distribution of the strain is quite inhomogeneous because nonuniformly application of the shear deformation. ${ }^{87)}$

Zisman et al. presented a modified design of the ECAD process named equal channel angular drawing of sheet metals $(\text { ECADS })^{90,91)}$ as shown in Fig. 9. The channel angle was selected to be $90^{\circ}$ and a reciprocated plunger was also used

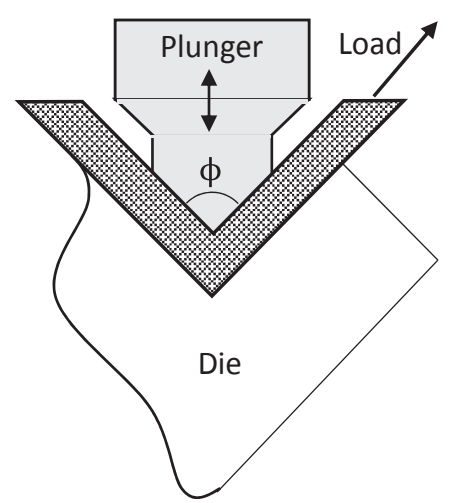

Fig. 9 Principal scheme of sheet processing by ECADS..$^{90,91)}$ 


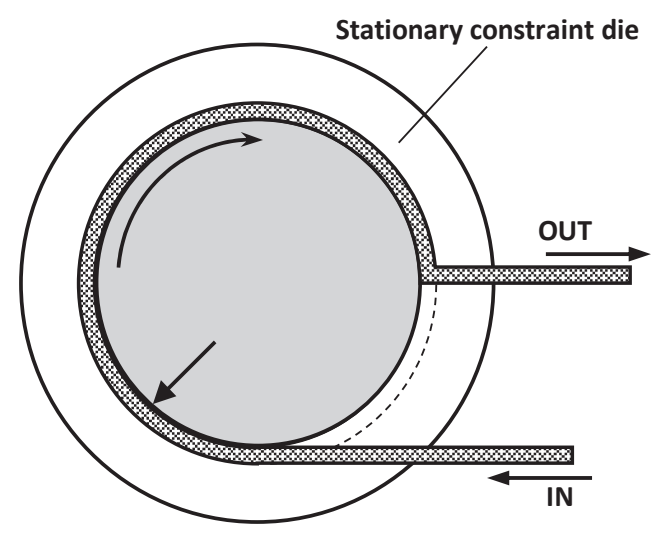

Fig. 10 A schematic of an ECAP-Conform facility in which the transformation to the square cross-section marked by the arrow. ${ }^{94)}$

besides drawing system. However, the cross-section area reduction and the sample elongation and flow instability may occur during the process. This process was utilized for processing of pure $\mathrm{Al}$ at room temperature on a strip of $1 \mathrm{~mm}$ in thickness and $40 \mathrm{~mm}$ in width. ${ }^{90,91)}$

\section{Continuous SPD Processes}

\subsection{ECAP-Conform}

For the continuous extrusion of wires, in the 1970s, the conform extrusion process was first investigated..$^{92,93)}$ Then, in 2004, Raab et al. has conveniently combined the conform extrusion with ECAP and developed the ECAP-Conform method as illustrated schematically in Fig. 10. ${ }^{94)}$ As shown, the work-piece is fed into the groove by a rotating grooved drum shaft. The work sample is fed continuously along the driven grooved drum by frictional forces in which the worksample rotates with the drum. However, the work-piece is constrained between the driven drum and stationary die into the groove. At the outlet, the work-piece is stopped at the angular zone in which it forced to experiences a shear deformation at a regular ECAP process. In this set-up, the deformation angle is the most commonly used channel intersection angle of $90^{\circ}$ similar to regular ECAP. However, other ECAP parameters, such as the strain rate, die curvature angle, and the die angle can also be implemented into the facility. ${ }^{88,94)}$ In this process, the transformation of the shape of the cross-section from circular to square or a bit crosssectional area reduction generate the drag force for pushing the sample into the ECAP die. However, the process is more influenced by the die and process parameters and it is hard to achieve appropriate parameter values. Important parameters are friction coefficient, area reduction, the channel angle, the groove shape, rotational speed, material properties, and the peripheral contact (which is $270^{\circ}$ in Fig. 10). This process was successfully used for the continuous production of $\mathrm{UFG} / \mathrm{NG}$ materials by several researchers and it is now industrially incorporated for production of nano Ti samples for medical implant applications. ${ }^{95)}$ My opinion, this set-up could effectively consider as the best continuous SPD method until now.

There are several other counterparts of the ECAP-conform process. In one of them, an extrusion was added at the exit of
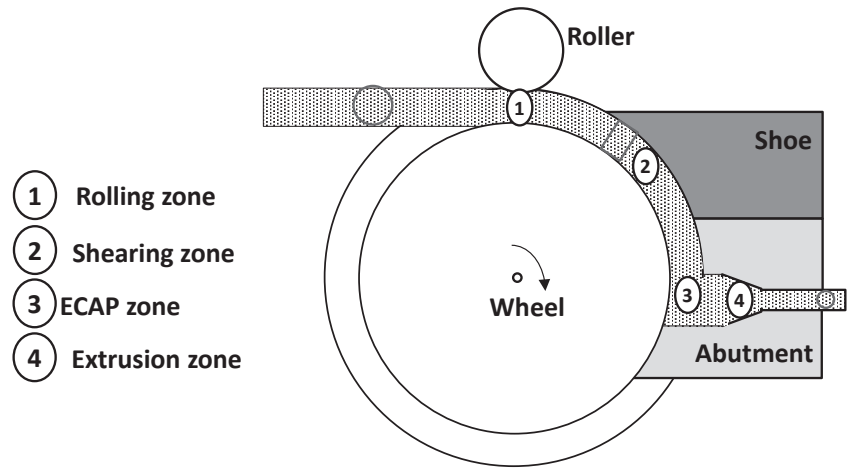

Fig. 11 The CONFORM process showing the application of sequential deformation modes of rolling, shear, ECAP, and extrusion. ${ }^{96)}$

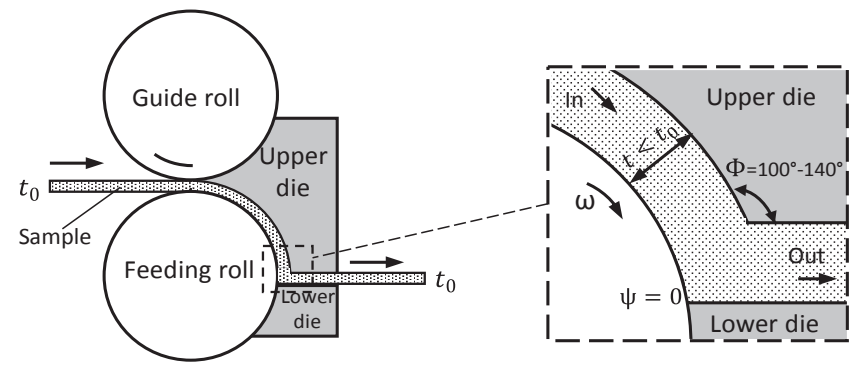

Fig. 12 The C2S2 process concept.

the process. The workpiece is fed by the driven drum towards the exit. The material experiences a series of plastic deformations similar to rolling, shear, ECAP, and extrusion as is seen in Fig. 11. The accumulated strain amount applied to the material in this method is more than that of conventional ECAP-conform. However, this process is less applicable and more complicated than ECAP-conform.

\subsection{Continuous confined strip shearing (C2S2)}

A continuous SPD technique was designed to apply the shear deformation into long strips termed the continuous confined strip shearing (C2S2) was introduced by Lee et al. in 2001 based on regular ECAP. ${ }^{97)}$ Though the process was variously nominated as equal-channel angular rolling $(\mathrm{ECAR})^{98-102)}$ or dissimilar channel angular pressing (DCAP), ${ }^{99,100,103)}$ the nature of them is almost the same. The concept of the $\mathrm{C} 2 \mathrm{~S} 2$ process is shown in Fig. 12. A specially designed feeding apparatus is used including guide and feeding rolls. The surface of the feeding roll is coarsened enough so that it can prepare the power needed for feeding the strip into the deformation ECAP channel. As shown in Fig. 9, the thickness of the outlet channel is slightly larger that of the inlet channel. The intersecting channel angle $(\Phi)$ is adjusted between $100^{\circ}$ to $140^{\circ}$ while the curvature angle $(\psi)$ is fixed to $0^{\circ}$. The strip with the initial thickness $\left(t_{0}\right)$ is fed between the rolls and its thickness is reduced $(t)$ upon enter into the gap and proceeds toward the deformation zone. Once the strip passes the outlet and the inlet channels intersect, it is thickening to its initial thickness $\left(t_{0}\right)$. The fact that the thickness of the metal strip at the outlet is the same as its initial thickness makes the possibility of repeating the process subsequently. ${ }^{104)}$ 


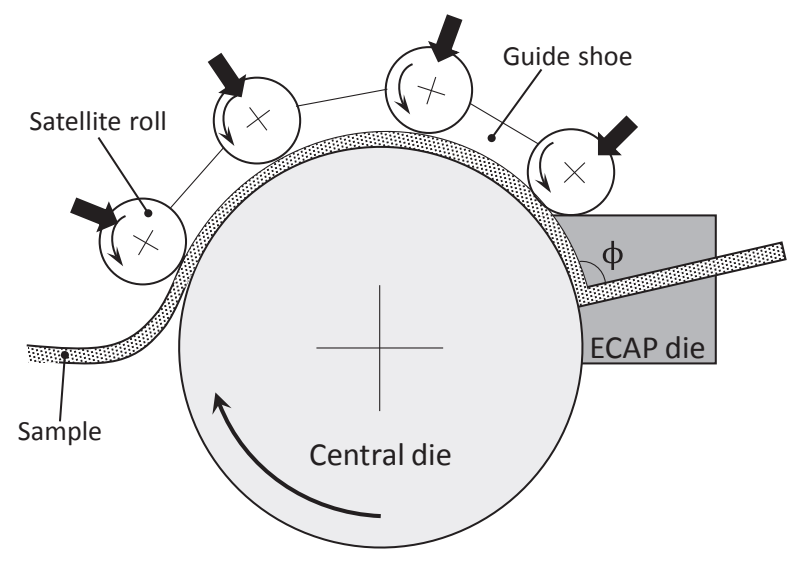

Fig. 13 The schematic of the conshearing process.

\subsection{Conshearing}

In 1997, the conshearing method illustrated schematically in Fig. 13 was introduced for processing of metallic strips. ${ }^{105-107)}$ As shown, the material is fed into the gap between a large central roller surrounded by satellite rollers by rotation of all rollers to generate enough extrusion force for deformation. Experiments on the conshearing processing of commercial purity aluminum samples demonstrated that optimum condition was obtained in the angle $\phi$ of $65^{\circ}$ in ECAP zone. ${ }^{107)}$ However, for successful operation a large number of rollers in required to deliver a large amount of extrusion force. This process was successfully implemented on an aluminium alloy ${ }^{108)}$ and the formation of shear texture was reported ${ }^{107)}$ making the process to use as a texturecontrolled method. This process is also applicable to coiled materials provided that some change in apparatus is made.

\subsection{Single roll angular rolling (SRAR)}

The SPD processes in which the strain is applied through equal channel angular have a common defect associated with the material velocity in different points in samples. ${ }^{74)}$ In these processes, the flow velocities between the upper and lower surfaces of the sample are different, and this results in a heterogeneous deformation. Such deformation can decrease material stability and weaken the microstructures and mechanical properties, which is harmful, especially for metal strips having a small thickness. To overcome this deficiency, another continuous SPD process named SRAR was presented to deliver highly uniform deformation throughout metallic strips by employing the peripheral shear deformation at the angular deformation zone. ${ }^{109)}$

A schematic of the SRAR process is depicted in Fig. 14. A circumferential groove is embedded inside the stationary die. The thickness of the circumferential groove is gradually decreased to create two useful phenomena. At first, the thickness reduction in the circumferential groove causes to provide the drag force to overcome the deformation resistance in the channel-angular region. Besides, the amount of deformation increases on the lower surface by the decrease in thickness before the channel-angular region as the deformation will balance in the upper and lower surfaces of the sample. Consequently, the SRAR process imposed a highly uniform strain on the sheets which cannot be enforced in ECAP-based operations. It should be mentioned that the

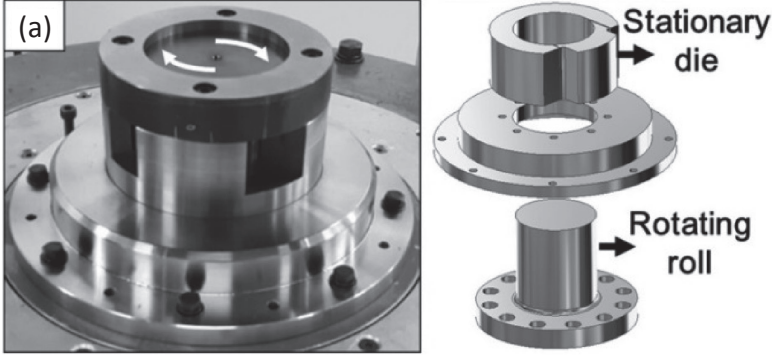

(b)

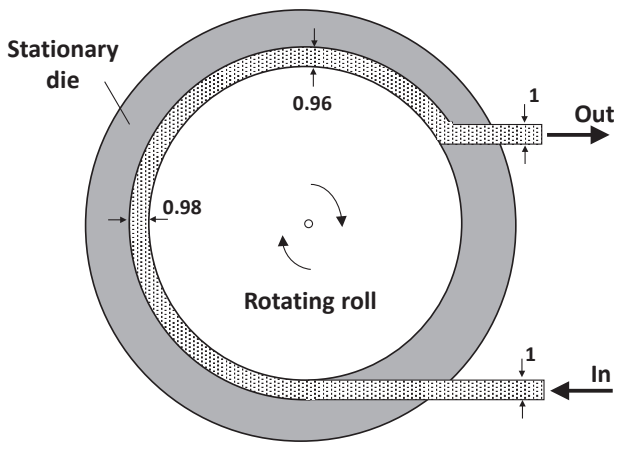

Fig. 14 (a) The SRAR process die setup on an HPT machine and (b) the cross-sectional view. ${ }^{109)}$

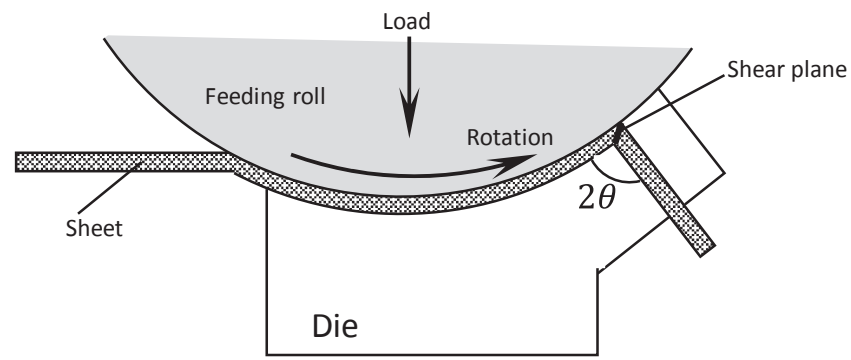

Fig. 15 Concept of the CFAE method consists of the die assembly, driving roll, and support block as the main parts of the setup. ${ }^{111)}$

thickness of groove is constant in the ECAP-Conform process and the transition of the cross-sectional shape from circular to square provides drag force. ${ }^{110}$

\subsection{Continuous frictional angular extrusion (CFAE)}

The schematic of the CFAE process with the same concept by ECAP-conform, C2S2 or ECAR is illustrated in Fig. 15. This process consists of an ECAP based die assembly combined with several innovative stages. In this method, a large diameter driving roll with almost high friction surface applies a normal pressure on the specimen with almost no plastic deformation. So, it feeds the sample into the ECAP region with high shear plastic deformation without a change in the cross-sectional area. However, it is possible to strain the material continuously even at a higher number of passes.

\subsection{Continuous severe plastic deformation (CSPD)}

One of the main drawbacks of regular ECAP process is the limitation of the sample length because of the high probability of the long press punch yielding/buckling. Therefore, any action for the reduction of process load on the press punch could increase the processable sample size. One of the ideas may lay from the application of a pulling 


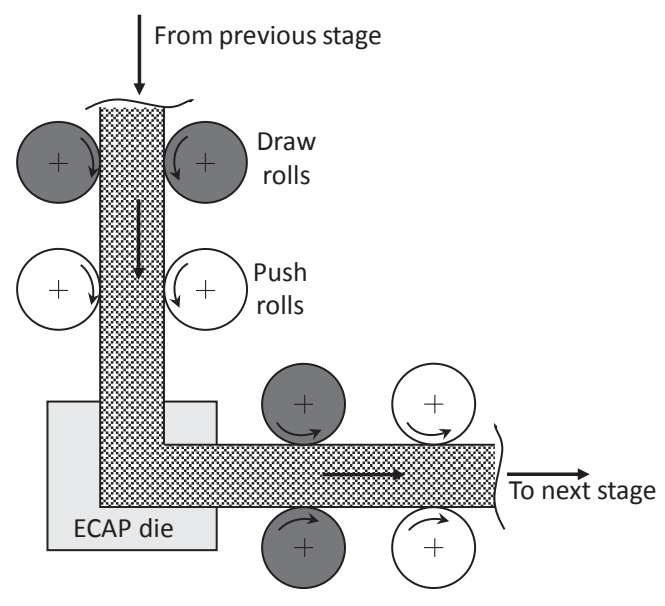

Fig. 16 Roller configuration for CSPD. ${ }^{12)}$

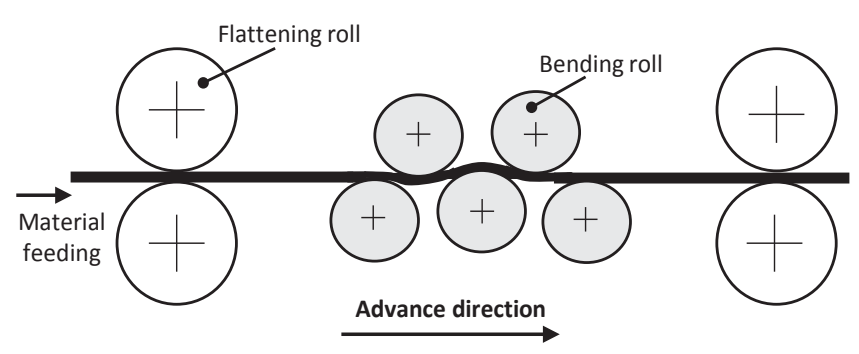

Fig. 17 Roll driven CCB machine. ${ }^{113,114)}$

force at the exit to reduce the pressing force at the inlet. A "push-pull" ECAP design was presented CSPD and is schematically shown in Fig. 16. ${ }^{112)}$ Two sets of rollers were used, one set for a push at the inlet and the other set for a pull at the outlet of the ECAP die. The number of pair rollers may be increased for more pushing or drawing force provided that the work sample not to be buckled before entrance or not to be yield after the exhausting. The ECAP die is almost short as shown in the figure, as long as the sample does not buckle at the unsupported part at the entrance/pushing side of the die. ${ }^{112)}$ Compared to the regular ECAP, the hydrostatic pressure would be smaller leading to low mechanical properties and high saturated grain size.

\subsection{Continuous cyclic bending (CCB)}

Continuous cyclic bending (CCB) as shown in Fig. 17 has been developed as a straining technique using specially designed rollers. ${ }^{113,114)}$ This process delivers bending strains on the strips/sheets in which the outer layer experiences more strains than the central area of the samples. So, it leads to a certain difference in stored strain energy between the central layers and surface. Thus, the subsequent annealing after straining by the CCB give the possibility of producing the gradient microstructure with the fine-grained central layer and the coarse-grained surface layer.

Though the process is continuous and simple there are still a large number of deficiencies. Unfortunately, the small value of strain, very small hydrostatic pressure, almost no shear strains, and existence of tensile strains at the surface make the process to be very useless. It is hard to consider the process as a continuous SPD method.

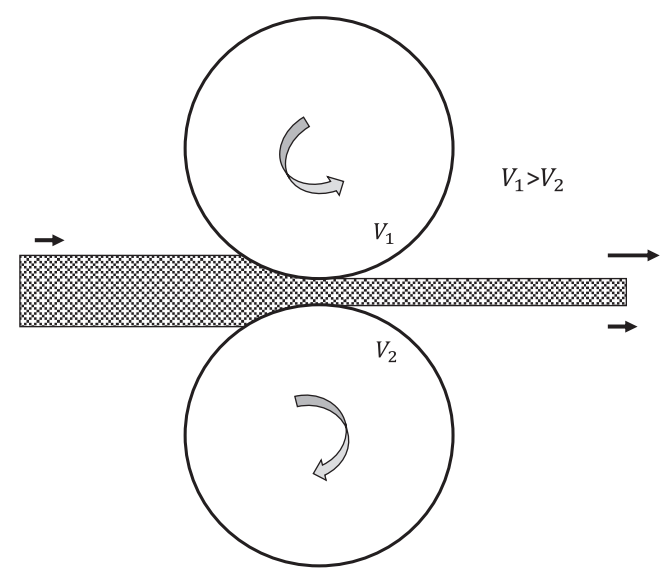

Fig. 18 Schematic of ASR or DSR method. ${ }^{119)}$

\subsection{Asymmetric rolling}

As shown in Fig. 18, the asymmetric rolling (ASR) or differential speed rolling (DSR) method is an almost severe straining process for sheet/strip samples. ${ }^{115-118)}$ Compare to regular rolling, the rolls have a different diameters or velocity leads to offer additional shear deformation into the metal. As is known, shear strains are more effective to refine the microstructure more than normal strains. However, the ASR could apply more equivalent strain than conventional rolling because of the existence of a shear component of strain. This process is influenced by several parameters such as friction conditions, different diameters and different rotational speeds of the upper and lower rolls. ${ }^{119)}$

\subsection{Caliber rolling (CAROL)}

Schematic illustration of CAROL is shown in Fig. 19. The lower roll and the counterpart upper roll have certain shape and dimensions. In CAROL process, the rolls have several calibers with various dimensions. A large strain can be accumulated by gradually decreasing the area reduction of the material using repetitive rollings. ${ }^{120)}$ In this process, the roll diameter is larger at the top portion than the bottom

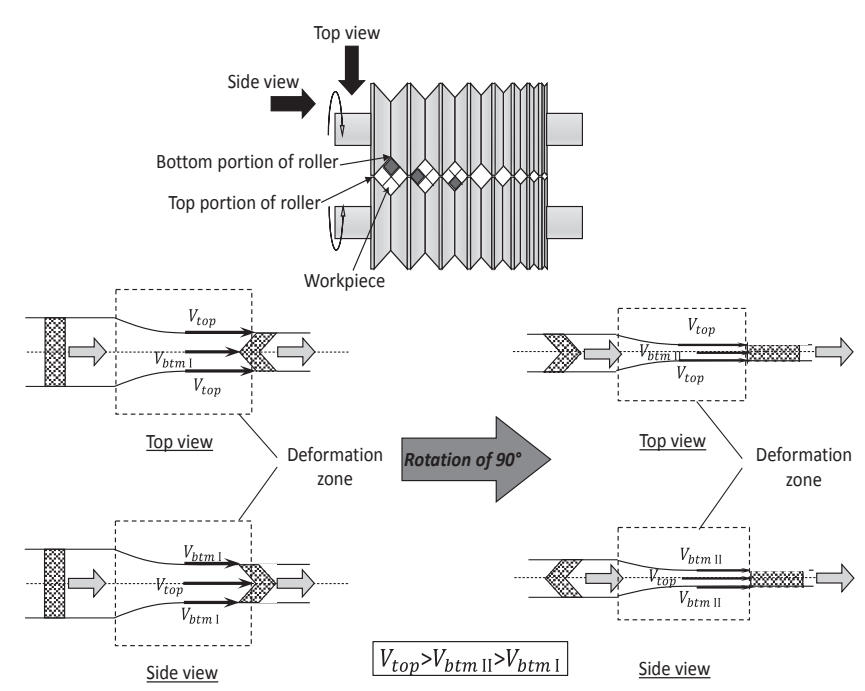

(a)

(b)

Fig. 19 The schematic illustration of the CAROL process, (a) first pass and (b) subsequent pass. ${ }^{120)}$ 
portion of each roll. Therefore, the peripheral speed at the outer area of rolls is more at the top $\left(V_{\text {top }}\right)$ than that at the bottom $\left(V_{b t m}\right)$. When a metallic rod is subjected to CAROL, the cross-sectional area of the billet is decreased and the inequality of $V_{b t m}$ and $V_{t o p}$ makes a definite shear strain as shown in Fig. 16. Between each rolling pass, the rolled sample is rotated $90^{\circ}$ around its axis to obtain more strain uniformity and is then rolled for the next pass. Between each rolling pass, the cross-sectional area is lessen again. The area reduction ration is remained constant between subsequent passes. However, the direction of shear is changed between rolling passes as illustrated in Fig. 19(b). Due to the lateral extension during the rolling, the real deformation mode may be more complicated. ${ }^{121)}$ Though one of main characteristhe tics of an SPD is that the cross section of the sample remains unchanged and calibre rolling may not classified as an SPD process, it could produce UFG/NG samples with high angle grain boundaries. So, caliber-rolling the process has got much attention due to its capability to produce large quantities bulk NG/UFG rods continuously. ${ }^{122,123)}$ Very long UFG carbon steel rods of over several kilometers were manufactured by the warm caliber rolling, from which the bolts of micron size are produced. ${ }^{124)}$

\subsection{Continuous high-pressure torsion (CHPT)}

An SPD process based on HPT which could be considered as a real continuous method was developed in 2010 for processing of metallic sheets with continuous HPT. Edalati et al. named it continuous high-pressure torsion (CHPT) process. ${ }^{125)}$ Figure 20 schematically illustrated the facility for the CHPT comprises of two lower and upper anvils. The lower anvil which is driven during the process has a flat surface with a roughened ring-shaped zone. Meanwhile, the upper anvil is settled during the process have a groove in half ring-shaped on its surfaces. To prepare a continuous material flow due to the difference in slippage, the surface roughness of the lower anvil is almost coarser than that of the upper anvil. At the beginning of the process, a U-shaped sample is placed on the lower anvil and the axial force is applied to offer a rigid contact between anvils and specimen. Then, the lower anvil is driven while the upper one is fixed so that a shear strain is applied into the sample under high pressure. Therefore, the material flows peripherally, accordingly. ${ }^{125)}$

\subsection{Planar high-pressure torsion (P-HPT)}

High-pressure torsion (HPT) is considered as a primary

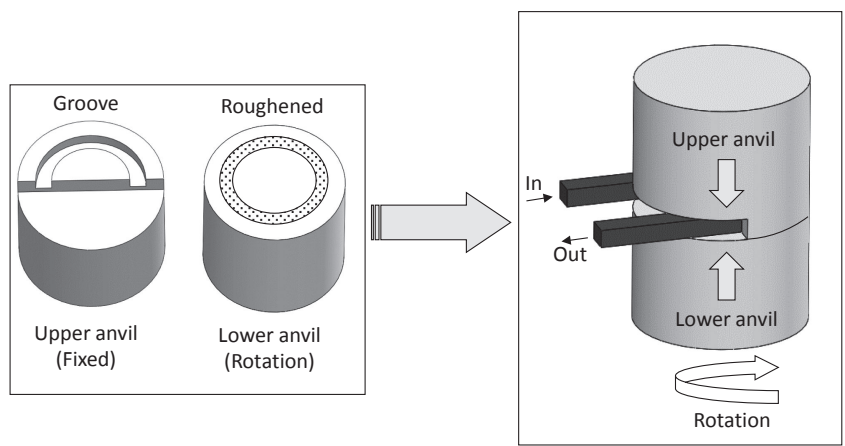

Fig. 20 Schematic illustration of CHPT. ${ }^{125)}$

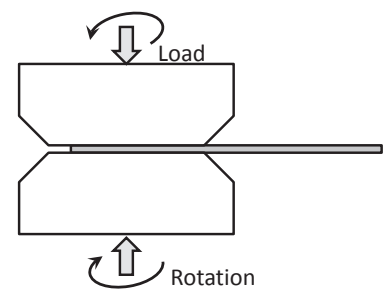

(a)

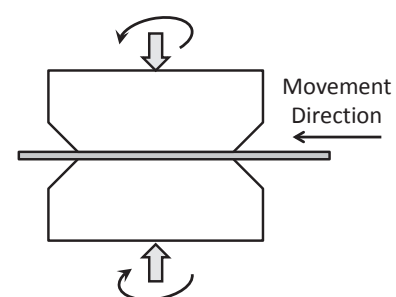

(b)

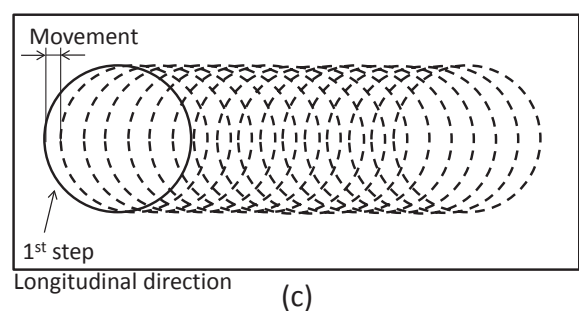

Fig. 21 The schematic of P-HPT process, (a) Beginning of the process, (b) Movement of the sheet in the next steps, (c) Top view to illustrate the deformation zones along the longitudinal direction in each step. ${ }^{126)}$

SPD process in which the high shear strain is applied to the material in the presence of the high hydrostatic pressure. Due to the favorable conditions of this process, some efforts have been performed to design an industrial mode of HPT process. One of the successful attempts is related to the research of Hohenwarter et al. ${ }^{126}$ ) that resulted in the presenting of Planar High-Pressure Torsion (P-HPT) for fabrication of UFG and NS continuous sheets.

The principle of the P-HPT process is depicted in Fig. 21. At first, the sheet is placed between two upper and lower anvils with a circular cross-section, and two anvils close together to impose a specific pressure on the sheet (Fig. 21(a)). This pressure creates a round-shaped area on the sheet with the same diameter as the upper anvil. The effect of the upper anvil in the first step is illustrated by the solid circle in Fig. 21(c). After that, one anvil is rotated against the other, which causes to apply the shear deformation into the sheet. The rotation angle should be selected in such a way that cracking between the deformed and undeformed area is prevented. After the first step, the sheet is unloaded and moved along the longitudinal direction by the specific distance. Then, the sheet is positioned under pressure loading, torsion and unloading again, and this procedure can be repeated multiple times along the longitudinal direction of the sheet. The movement of the sheet between two consecutive steps is much smaller than the radius of the upper anvil so that the locally shear strain in every step is accumulated to the shear strain introduced by the preceding deformation steps.

\subsection{Repetitive corrugation and straightening (RCS)}

Continuous RCS method consists of corrugation stage followed by straightening as shown in Fig. 22. It is clear that the continuous RCS process could be easily adapted to a rolling mill. In the corrugation stage, the metallic sheet/strip is corrugated between two gear-shaped rollers and in the straightening stage, it flattened between two flat rolls. ${ }^{127)}$ The total plastic strain of the RCS is the sum of that for each stage in which the plastic strain is the same for both stages. 


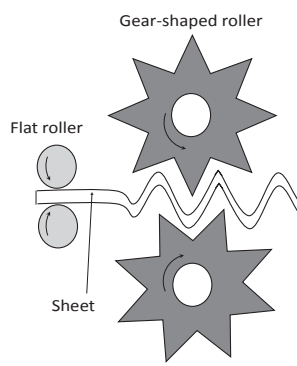

(a)

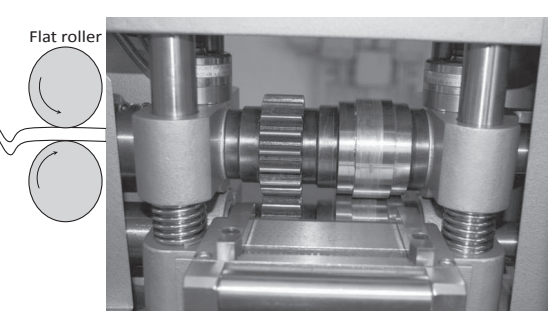

(b)
Fig. 22 Schematic of continuous RCS process ${ }^{127)}$ (a) and apparatus ${ }^{128)}$ (b).

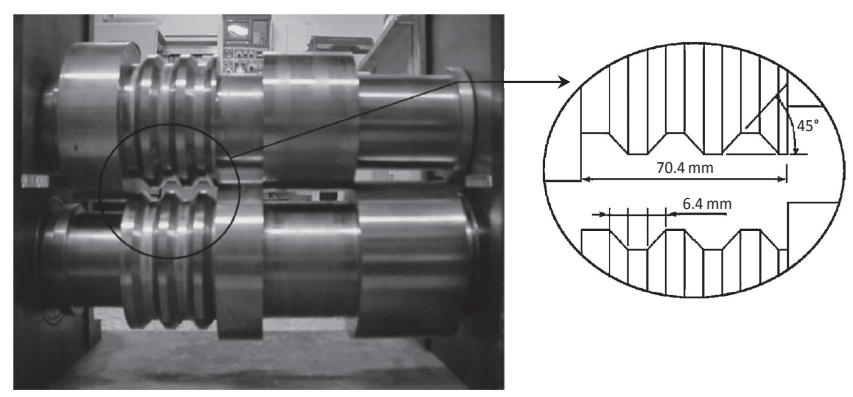

Fig. 23 The CGR apparatus and configuration of the roll. ${ }^{129)}$

The RCS method looks to be very effective and simple at first glance. Careful examination may exhibit that there is tensile stress mode at the free surfaces leading to initiation and formation of defects, and cracks. Also, relatively low hydrostatic pressure may facilitate the propagation of micro and nano-voids during the process. This may terminate the capability of the process for application of very large strains which is one of the main criteria of an effective SPD method.

\subsection{Constrained groove rolling (CGR)}

CGR as a continuous SPD method based on its discontinuous counterpart (constrained groove pressing) is developed as illustrated in Fig. 23 consists of two sets of grooved and flat rolls. A sheet/strip/plate sample is corrugated and then flattened continuously between the rolls. At the corrugation stage, the workpiece is pressed between the asymmetrically grooved rolls in which the flat regions of the workpiece remain undeformed while the inclined regions are subjected to shear deformation. Then, at the flattening stage, the deformed regions experience reverse shear deformation while the undeformed regions remain still unchanged. Afterward, the workpiece is rotated by $180^{\circ}$ and the undeformed regions are deformed by the rolls in which both stages are repeated to finish the first pass CGR. The CGR looks more practical since the material can be continuously deformed. ${ }^{129)}$ However, free deformation and low hydrostatic pressure limit its industrial applications because of the less mechanical properties compared to most continuous SPD methods such as ECAP conform.

\subsection{Accumulative roll bonding (ARB)}

Saito et al. have developed the ARB in 1998 based on the conventional rolling as a continuous metal forming process ${ }^{130)}$ with the principles illustrated in Fig. 24. In this

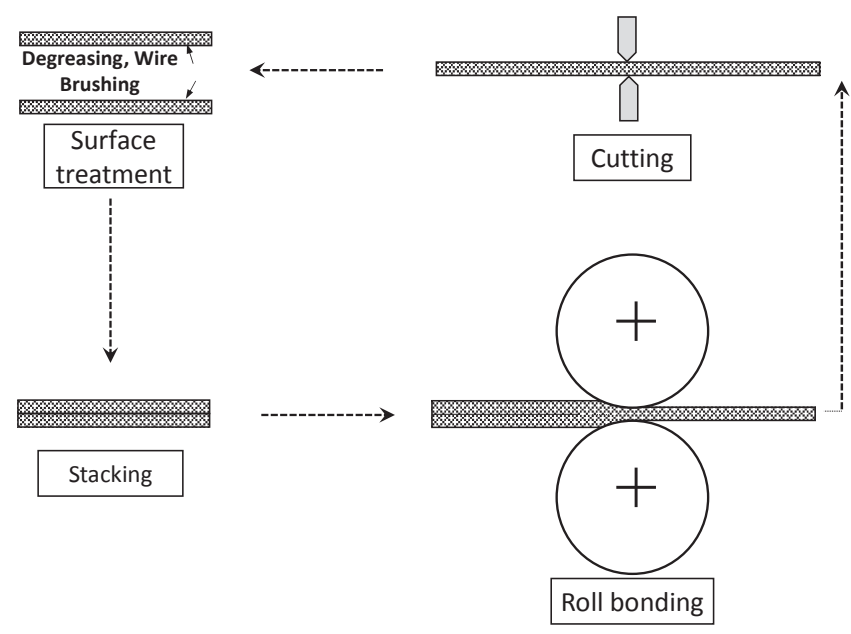

Fig. 24 Schematic of the ARB method. ${ }^{130}$ )

method, conventional roll bonding with 50\% thickness reduction is repeatedly done on the stacked two strips with the same thicknesses. For increasing the strength of the bond, the joint surfaces are cleaned and wire brushed. Then, the length of the rolled metal is cut into two halves which stacked and roll bonded after surface treatment. ${ }^{131)}$ In ARB, the rolling process is considered as a bonding stage beside its primary deformation function. ${ }^{132)}$

After $n$ ARB passes, the final thickness is $t_{0} / 2^{n}$ where $t_{0}$ is the initial thickness. ${ }^{130)}$ Accumulative roll bonding and folding was then introduced for speed up the process by combining the advantages of folding and ARB processes. ${ }^{133)}$

\subsection{Repetitive corrugation and straightening by rolling (RCSR)}

As shown in Fig. 25 RCSR is a continuous straining process similar to CGR except that it utilizes special corrugated rolls. ${ }^{134)}$ In this process, a strip/sheet sample is rolled between two asymmetrically wavy grooved rolls so that some parts of the work-piece are strained, firstly. Afterward, it is flattened between flat rolls. At the second half-pass, the sample is rotated by $180^{\circ}$ and the same procedure done at the first half-pass is repeated so that the whole sample is strained. The gap between the rolls could be adapted for applying additional plastic deformation which

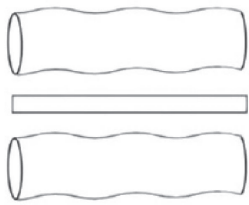

(a)

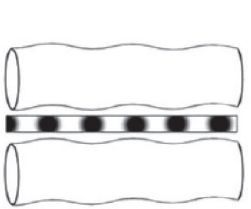

(d)

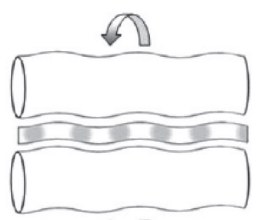

(b)

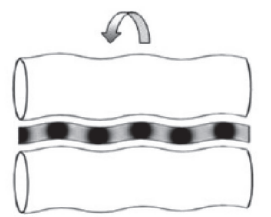

(e)

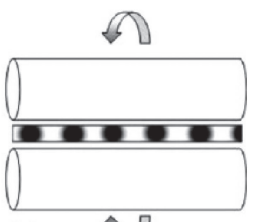

(c)

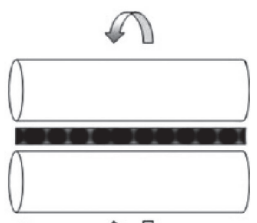

(f)
Fig. 25 Schematic of the RCSR process. ${ }^{134)}$ 
may lead to reducing the thickness of the workpiece. Therefore, the specimen is expected to be thinner, wider, or longer than its original size. Though the process was done at laboratory scale it can be easily scaled up for production on the industrial scale. This process contains several privileges such as continuity, simplicity, and suitability for the industrial application. Meantime, the major disadvantageous are relatively the dimensional changes, nonhomogeneous structure, and the probability of formation of cracks and defects due to lower hydrostatic stresses.

\subsection{Severe torsion straining (STS)}

A dieless continuous process was developed as a severe torsion straining (STS) process shown schematically in Fig. 26. ${ }^{135)}$ The idea is similar to regular dieless wire drawing systems. The main core of the process is simultaneous locally heating and cooling where a twist is applied from a side of the long sample to offer shear strain on the heated zone. This heating/cooling system or the sample

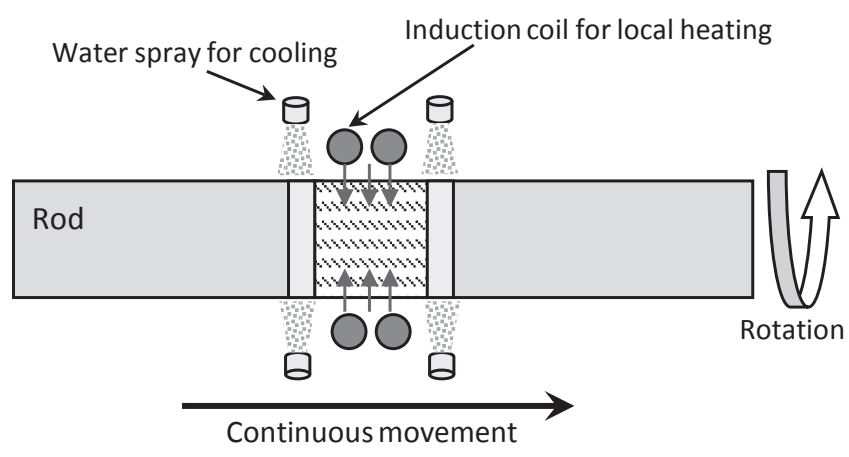

Fig. 26 Schematic illustration of STSP. ${ }^{135)}$

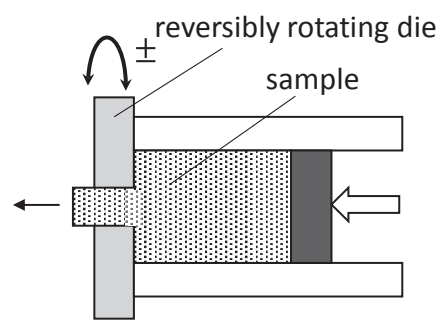

(a)

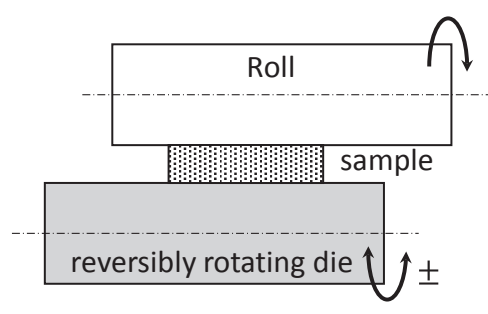

(c) is proportionally moved gradually to scan the whole length of the sample. The locally heated area must be narrow for applying the torsion strain efficiently where the rotational speed should be faster than the translational moving speed of the rod.

However, a continuous grain refining method can be obtained by STSP that can be implemented for other sample shapes such as wires and tubes. ${ }^{135)}$ It seems that there are several deficiencies in the process including:

- Larger grain size as a result of high temperature and dynamic recrystallization.

- Very low surface quality like wavy or roughened.

- Higher surface and substrate defects and cracks as a result of very small hydrostatic pressure.

- Low mechanical properties as a result of very small hydrostatic pressure.

\subsection{KoBo process}

Korbel and Bochniak proposed an industrial SPD process, called KoBo. ${ }^{136,137)}$ KOBO method could be utilized during different typical metal forming processes such as forging, extrusion, rolling or drawing which guarantees homogeneous and highly fragmented structure of products. ${ }^{138)}$ In this method, a cyclic variation in the deformation path via combined reversible torsion and different conventional metal forming occurs as shown in Fig. 27. This procedure makes the extrusion process to be conducted at cold working state at a low temperature in which the material can be extruded at higher extrusion ratio at higher strain rates (condition for hot working) without preheating. At the same time, UFG/NG structure with very good mechanical properties is produced. However, very limited data on experimental evidence on this process can be found in the literature.

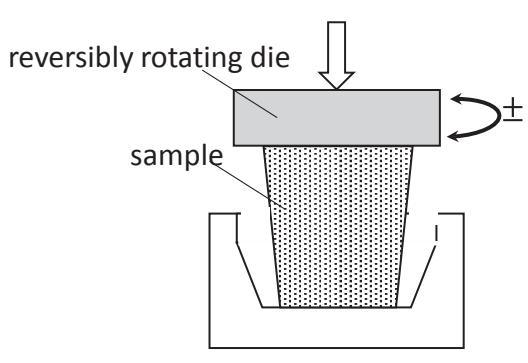

(b)

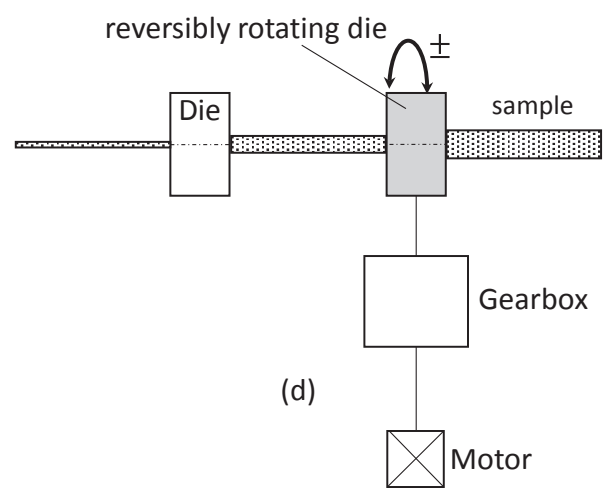

Fig. 27 Schematic illustrations of some metal forming process such as Forging, Extrusion, Drawing and Rolling, equipped by KOBO method. ${ }^{136,137)}$ 


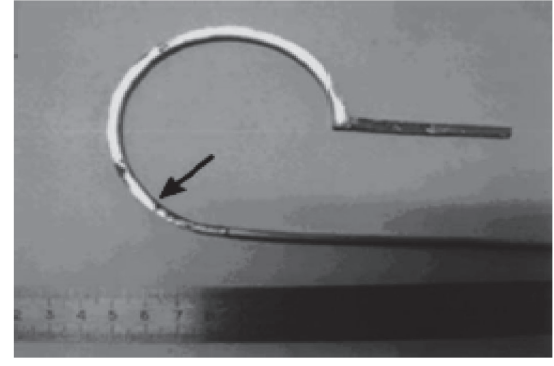

(a)

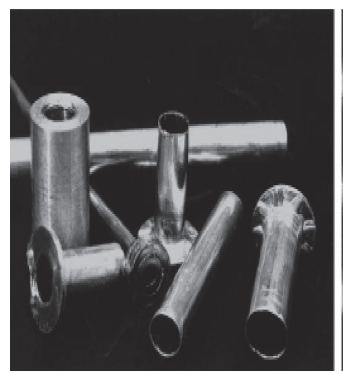

(c)

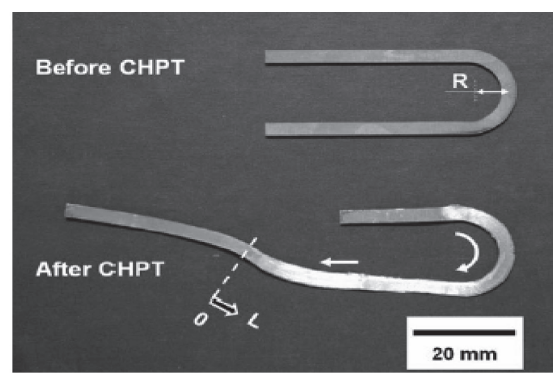

(b)

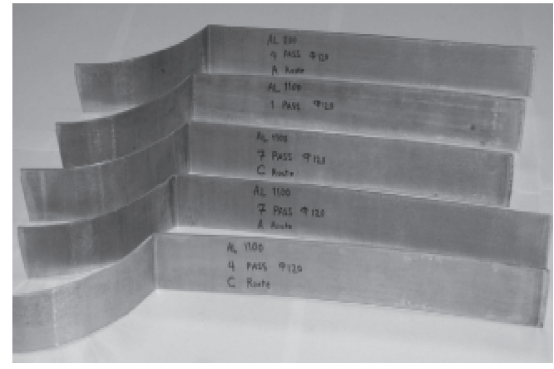

(d)

Fig. 28 Some industrial-scale samples produced in different SPD processes, (a) ECAP-Conform, ${ }^{94)}$ (b) CHPT, ${ }^{125)}$ (c) KOBO, ${ }^{136)}$ and (d) ECAR. ${ }^{102)}$

In KoBo method the metal experiences, high pressure applied implied simultaneously with oscillating torsion with an amplitude about $5-7^{\circ}$ and frequency of several Hertz combined with conventional metal forming process. Such a complex plastic straining leads to a high heterogeneous flow of the materials in strongly short deformation zone. However, a drastic reduction in the extrusion force depending on the amplitude and frequency of the die rotation deforms the materials up to very large strains at low temperatures. The material billet tolerates reversible plastic twisting just before entering to the extrusion deformation zone during the KoBo extrusion process. ${ }^{139)}$

\section{Discussion}

\subsection{Size}

One of the main challenges in SPD processing is the sample size including the length and cross-sectional area. The size of the final product is the most critical factor in determining which SPD method has more potential for industrial applications. The semi-continuous operations are attributed to those by which can process almost large-size UFG or NS products, but in the continuous methods, the samples are theoretically infinite in length.

In most of the semicontinuous processes, the possibility of punch or sample yielding or buckling makes the main limitation. The potential of buckling/yielding increases with the increase in the deformation load. Therefore, any action that decreases the deformation load can improve conditions to produce larger industrial products. As a role, the largest sample size achieved from continuous and the smallest from discontinuous processes. A prominent example is related to HCEE process in which the friction force and deformation load are reduced to increase the sample size $(1 / \mathrm{d})$ from $\sim 5$ in regular CEE to more than $10 \mathrm{~mm}$ in HCEE. ${ }^{80,140)}$
In some of the semicontinuous processes in which drawing is applied at the outlet like ECAD, the tensile stress at the outlet side should not exceed from the yield strength of the material otherwise the plastic deformation is limited by yielding the sample. For example, the angle between input and output channels in ECAD process should be larger to prevent different damages in final products. Besides, low hydrostatic stresses are expected which limits the workability or maximum applicable strain and a limited number of passes. This leads to less grain refinement and large saturated grain size. Despite the limitations in tension stress in drawing base methods, the processing of very long samples in materials with high formability (such as carbon steel) has been performed in the SD process. ${ }^{141)}$ In continuous processes such as ECAP conform, ECAR and ARB, since the pushing or dragging of the sample are performed by rollers and the sample is forced into the deformation area, there is no need for pull/push forces to the sample at both sides of the deformation zone. Therefore, the workability is almost higher than the earlier example and it could produce a very long sample.

Some of the SPD processed large samples are shown in Fig. 28. A continuous rod in every stage of the ECAPConform process is shown in Fig. 28(a). As seen in Fig. 28(b), U-shaped $\mathrm{Cu}$ sample with a rectangular crosssection has been deformed in the CHPT process to obtain the large products. Tubes from 3003 aluminum alloy achieved by the KOBO extrusion are shown in Fig. 28(c). Figure 28(d) illustrates the samples after different passes of the ECAR method in which it is possible to process the UFG and NS sheets applied for wide industrial applications.

\subsection{Microstructure and properties}

The properties of the products in SPD methods are very critical to achieve a working sample in industrial application 
to provide the required functions. The properties are specified by the microstructure evolution during the SPD process. ${ }^{142)}$ Hence it is worthy to identify different methods in terms of microstructural, mechanical and physical alteration. ${ }^{74)}$ Some factors can influence on microstructure and properties of the final product that will be explained in the following.

The amount of strain applied in SPD methods is the most crucial factor to specify the microstructure and properties of processed samples. From the theory of plasticity, it can be demonstrated that the state of stress can be divided into hydrostatic and deviator stresses that represent the shear stresses within the total state of stress. The deviator stress provides the redundant work playing the primary role to refine the microstructure and improving the properties. ${ }^{143)}$ So more redundant work (more shear stress) can result in more grain refinement. ${ }^{64)}$

Many types of research have verified that the greater compressive hydrostatic stress improves the workability of a material. The ECAP process was investigated with and without back pressure to find out how compressive hydrostatic stress influences on workability. ${ }^{144,145)}$ Unlike tension stress, compressive stress imposed during the deformation process prevents the initiation of microcracks and closing of small cavities and cracks (or limiting their growth), thus enhancing workability. ${ }^{146)}$ Hence, in the presence of high hydrostatic pressure, the applying of large effective strain will be possible, and the brittle metals that are deformed difficulty under normal condition will be processed by SPD methods without failure. ${ }^{147)}$ The influences of hydrostatic pressure on grain size should be discussed. The saturated grain size is attributed to the smallest grain size obtainable in SPD processes. Strain, strain rate, working temperature, alloying, stacking fault energy (SFE) and hydrostatic pressure are the main factors determining the saturation grain refinement in the SPD process. ${ }^{64,148,149)}$

Because the final microstructure and grain size specify the final properties, which are very important in the industrial application, it is expected that the factors influencing the microstructure can determine the final properties. So the influences of effective strain and hydrostatic pressure on the final properties should be discussed. Figure 29 depicts the influences of effective strain and compressive hydrostatic stress on the final grain size of 1000 series Aluminum investigated in the previous researches. The HCEE, ECAR, and Conshearing are compared regarding the final grain size.

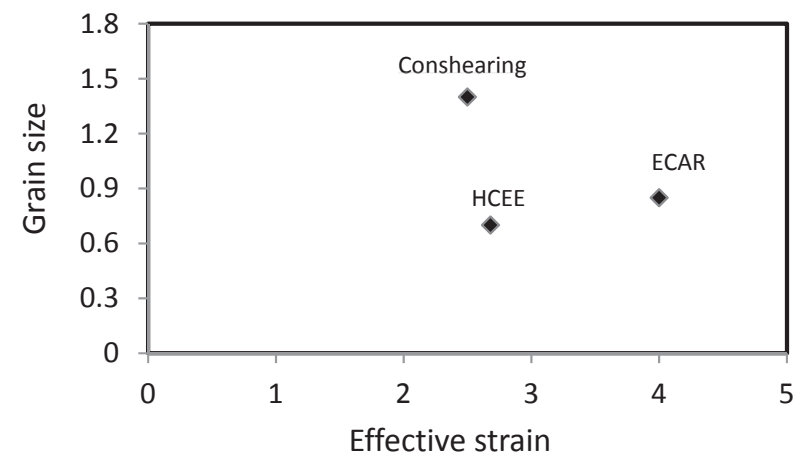

Fig. 29 The diagram showing the influence of effective strain and Hydrostatic pressure on grain size.
As is evident, although the effective strain in Conshearing and HCEE samples are approximately equal, the final grain size attained in conshearing is twice of that one in HCEE. ${ }^{150,151)}$ The reason for this case is concerned with the difference in hydrostatic pressure in these two processes. In general, the hydrostatic pressure in processes based on pressing is more than that of another process; therefore, this can help to attain the smaller grain size in the final products. An interesting comparison is related to the ECAR process in which the effective strain is about twice of the one in HCEE, but the grain size in ECAR is still more than that of HCEE. The copper-samples processed through P-HPT and HPTE are mentioned to show the effect of hydrostatic pressure on grain size. Although the amount of equivalent strain imposed to the material is 19 and 15.7 in the HPTE and P-HPT, respectively, the final grain size in HPTE in more than that of P-HPT. The high hydrostatic pressure remains stable during the process in P-HPT process compared to the HPTE, which causes to enhance less saturated grain size. ${ }^{14,152)}$ This subject should be investigated in different materials to enhance further information and comprehensive outcome.

As shown in Fig. 30, the HCEE and CCDF based on pressing have more ultimate strength than those of ECAR based on rolling and ECAD based on the drawing. The level of hydrostatic pressure is excellent, moderate and poor in HCEE (or CCDF), ECAR and ECADF, respectively; therefore, the strength of sample processed in HCEE (or CCDF) is generally more than others.

Because the feasibility of microcrack formation and growth is high in the processes based on drawing, it is evident that the strength of the sample processed in ECAD is lower than those of others. Limited experimental works performed in industrial SPD processes about the influences of hydrostatic pressure on strength. However, it can be concluded that the high hydrostatic pressure in P-HPT compared to the HPTE result in more hardness in coppersamples. ${ }^{14,152)}$ Another valuable property is related to the elongation that due to the abovementioned points, it is expected that the workability of final products in pressing methods is more than others. ${ }^{76,150,153)}$ So it is vital to design an industrial SPD process which can impose high effective strain in the presence of high hydrostatic pressure.

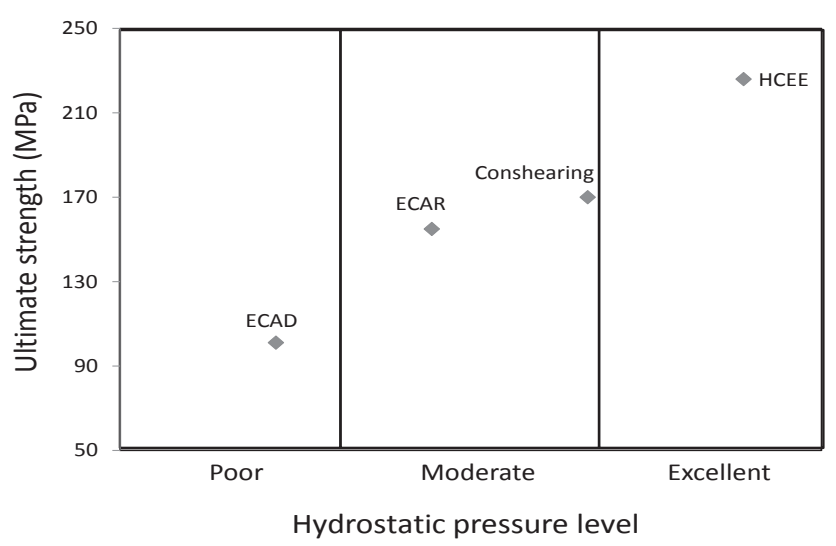

Fig. 30 The diagram showing hydrostatic pressure effect on ultimate strength in Aluminum series 1xxx. 


\section{Conclusion}

This article provides a comprehensive review on industrial SPD methods and categorizes them. One of the main challenges in SPD processing is the sample size including the length and cross-sectional area. The size of the final product is the most critical factor in determining which SPD method has more potential for industrial applications. The semi-continuous operations are attributed to those by which can process almost large-size UFG or NS products, but in the continuous methods, the samples are theoretically infinite. Additionally, the metallurgical and mechanical properties of final products were compared to show which factors are critical to present an effective method. It should be noted that the amount of strain and hydrostatic pressure, which can be achieved in the process, should be as much as possible to obtain the excellent properties in the final industrial samples. The technical characteristics of SPD performed in this article can help the researcher to promote the outcomes of previous investigations.

\section{Acknowledgments}

This work was supported by Iran National Science Foundation (INSF).

\section{REFERENCES}

1) T.C. Lowe and R.Z. Valiev: Investigations and Applications of Severe plastic Deformation, (Springer Science \& Business Media, 2012).

2) R. Valiev: Nat. Mater. 3 (2004) 511.

3) R.Z. Valiev, Y. Estrin, Z. Horita, T.G. Langdon, M.J. Zechetbauer and Y.T. Zhu: JOM 58(4) (2006) 33-39.

4) P.W. Bridgman: J. Appl. Phys. 14 (1943) 273-283.

5) P.W. Bridgman: J. Appl. Phys. 17 (1946) 692-698.

6) Y. Estrin and A. Vinogradov: Acta Mater. 61 (2013) 782-817.

7) G. Faraji, H.S. Kim and H.T. Kashi: Severe Plastic Deformation, ed. by G. Faraji, H.S. Kim and H.T. Kashi, (Elsevier, 2018) pp. 1936.

8) V.M. Segal, V.I. Reznikov, A.E. Drobyshevskiy and V.I. Kopylov: Russ. Metall. 1 (1981) 99-105.

9) T.G. Langdon: Mater. Sci. Eng. A 503 (2009) 6-9.

10) E. Bagherpour, N. Pardis, M. Reihanian and R. Ebrahimi: Int. J. Adv. Manuf. Technol. 100 (2019) 1647-1694.

11) V. Segal: Materials 11 (2018) 1175.

12) A.P. Zhilyaev and T.G. Langdon: Prog. Mater. Sci. 53 (2008) 893 979.

13) S. Zherebtsov, G. Salishchev, R. Galeyev, O. Valiakhmetov, S.Y. Mironov and S. Semiatin: Scr. Mater. 51 (2004) 1147-1151.

14) Y. Ivanisenko, R. Kulagin, V. Fedorov, A. Mazilkin, T. Scherer, B. Baretzky and H. Hahn: Mater. Sci. Eng. A 664 (2016) 247-256.

15) A. Vinogradov and S. Hashimoto: Mater. Trans. 42 (2001) 74-84.

16) B. Mani, M. Jahedi and M.H. Paydar: Mater. Sci. Eng. A 528 (2011) 4159-4165.

17) K. Nakashima, Z. Horita, M. Nemoto and T.G. Langdon: Mater. Sci. Eng. A 281 (2000) 82-87.

18) G. Raab: Mater. Sci. Eng. A 410 (2005) 230-233.

19) Y. Nishida, H. Arima, J.-C. Kim and T. Ando: Scr. Mater. 45 (2001) 261-266.

20) A. Azushima and K. Aoki: Mater. Sci. Eng. A 337 (2002) 45-49.

21) S. Sepahi-Boroujeni and F. Fereshteh-Saniee: J. Mater. Sci. 50 (2015) 3908-3919.

22) A. Rosochowski, L. Olejnik, J. Richert, M. Rosochowska and M. Richert: Mater. Sci. Eng. A 560 (2013) 358-364.

23) M. Ebrahimi, H. Gholipour and F. Djavanroodi: Mater. Sci. Eng. A
650 (2016) 1-7.

24) Q. Wang, Y. Chen, J. Lin, L. Zhang and C. Zhai: Mater. Lett. 61 (2007) 4599-4602.

25) M. Jahedi and M.H. Paydar: Mater. Sci. Eng. A 527 (2010) 52735279 .

26) M. Richert, Q. Liu and N. Hansen: Mater. Sci. Eng. A 260 (1999) 275-283.

27) J. Lin, Q. Wang, L. Peng and T. Peng: Mater. Trans. 49 (2008) 10211024.

28) N. Pardis, B. Talebanpour, R. Ebrahimi and S. Zomorodian: Mater. Sci. Eng. A 528 (2011) 7537-7540.

29) L. Zaharia, R. Chelariu and R. Comaneci: Mater. Sci. Eng. A 550 (2012) 293-299.

30) M.I. Latypov, Y. Beygelzimer and H.S. Kim: Mater. Trans. 54 (2013) 1587-1591.

31) Y. Beygelzimer, D. Orlov and V. Varyukhin: Ultrafine Grained Materials II, (Wiley, Hoboken, 2002) pp. 297-304.

32) D. Orlov, Y. Beygelzimer, S. Synkov, V. Varyukhin, N. Tsuji and Z. Horita: Mater. Trans. 50 (2009) 96-100.

33) Y. Beygelzimer, D. Prilepo, R. Kulagin, V. Grishaev, O. Abramova, V. Varyukhin and M. Kulakov: J. Mater. Process. Technol. 211 (2011) 522-529.

34) F. Rahimi, A. Eivani and M. Kiani: Mater. Des. 83 (2015) 144-153.

35) S. Khoddam, A. Farhoumand and P. Hodgson: Mater. Sci. Eng. A 528 (2011) 1023-1029.

36) G. Faraji, M. Mashhadi and H.S. Kim: Mater. Sci. Eng. A 528 (2011) 4312-4317.

37) K. Kim and J. Yoon: Mater. Sci. Eng. A 578 (2013) 160-166.

38) H. Alihosseini, M.A. Zaeem and K. Dehghani: Mater. Lett. 68 (2012) 204-208.

39) M. Montazeri-Pour, M. Parsa, H. Jafarian and S. Taieban: Mater. Sci. Eng. A 639 (2015) 705-716.

40) H. Lianxi, L. Yuping, W. Erde and Y. Yang: Mater. Sci. Eng. A 422 (2006) 327-332.

41) Z. Zhang, Y. Du, G. Zhang, Z. Yan, J. Yu and M. Meng: Mater. Trans. 59 (2018) 669-673.

42) J. Liu, Q. Wang, H. Zhou and W. Guo: J. Alloys Compd. 589 (2014) 372-377.

43) N. Kamikawa and T. Furuhara: J. Mater. Process. Technol. 213 (2013) 1412-1418.

44) X. Zhao, J.-f. Wang and T.-f. Jing: J. Iron Steel Res. Int. 14(5) (2007) $52-55$.

45) R. Kocich, M. Greger, M. Kursa, I. Szurman and A. Macháčková: Mater. Sci. Eng. A 527 (2010) 6386-6392.

46) R. Kocich, A. Macháčková and L. Kunčická: Mater. Sci. Eng. A 612 (2014) 445-455

47) M. Ensafi, G. Faraji and H. Abdolvand: Mater. Lett. 197 (2017) 1216.

48) O. Bouaziz, Y. Estrin and H.-S. Kim: Rev. Metall. 104 (2007) 318322.

49) D.H. Shin, J.J. Park, Y.S. Kim and K.T. Park: Mater. Sci. Eng. A 328 (2002) 98-103.

50) A. Shahmirzaloo, G. Faraji, M. Safari and S. Mohammadinejad: Mater. Sci. Technol. 34 (2018) 1669-1678.

51) M. Borhani and F. Djavanroodi: Mater. Sci. Eng. A 546 (2012) 1-7.

52) R.S. Mishra, M. Mahoney, S. McFadden, N. Mara and A. Mukherjee: Scr. Mater. 42 (1999) 163-168.

53) L.S. Tóth, M. Arzaghi, J.J. Fundenberger, B. Beausir, O. Bouaziz and R. Arruffat-Massion: Scr. Mater. 60 (2009) 175-177.

54) M.S. Mohebbi and A. Akbarzadeh: Mater. Sci. Eng. A 528 (2010) $180-188$.

55) G. Faraji, M.M. Mashhadi and H.S. Kim: Mater. Lett. 65 (2011) 3009-3012.

56) G. Faraji, M.M. Mashhadi and H.S. Kim: Mater. Trans. 53 (2012) 812.

57) G. Faraji, A. Babaei, M.M. Mashhadi and K. Abrinia: Mater. Lett. 77 (2012) 82-85.

58) M. Mesbah, F. Fadaeifard, A. Karimzadeh, B. Nasiri-Tabrizi, A. Rafieerad, G. Faraji and A.R. Bushroa: Met. Mater. Int. 22 (2016) 1098-1107.

59) J.T. Wang, Z. Li, J. Wang and T.G. Langdon: Scr. Mater. 67 (2012) 
810-813.

60) H. Torabzadeh Kashi and G. Faraji: Modares Mech. Eng. 15(8) (2015) 411-416.

61) O. Shapourgan and G. Faraji: Proc. Inst. Mech. Eng., B: J. Eng. Manuf. 230 (2016) 1845-1854.

62) F. Abu-Farha: Scr. Mater. 66 (2012) 615-618.

63) H. Abdolvand, H. Sohrabi, G. Faraji and F. Yusof: Mater. Lett. 143 (2015) 167-171.

64) G. Faraji and H.S. Kim: Mater. Sci. Technol. 33 (2017) 905-923.

65) D. Orlov, G. Raab, T.T. Lamark, M. Popov and Y. Estrin: Acta Mater 59 (2011) 375-385.

66) H. Abdolvand, G. Faraji, J.S. Karami and M. Baniasadi: Bull. Mater Sci. 40 (2017) 1471-1479.

67) S. Amani, G. Faraji, H. Kazemi Mehrabadi, K. Abrinia and H. Ghanbari: J. Alloys Compd. 723 (2017) 467-476.

68) L.O.A. Rosochowski: Proceedings of the 10th International Conference on Material Forming, Esaform2007, Proceedings 907, ed. by E. Cueto and F. Chinesta, (American Institute of Physics, 2007) pp. 653-658.

69) A.R.E.L.D.L. Olejnik: Proc. of the 4th International Conference on Advances in Production Engineering, APE'07, (Warsaw Univ. of Technology, 2007) pp. 139-146.

70) L.O.A. Rosochowski and M.W. Richert: Mater. Sci. Forum 584-586 (2008) 139-144.

71) A.R.L. Olejnik and M.W. Richert: Mater. Sci. Forum 584-586 (2008) 108-113.

72) A. Medvedev, H.P. Ng, R. Lapovok, Y. Estrin, T.C. Lowe and V.N. Anumalasetty: Mater. Lett. 145 (2015) 308-311.

73) S. Lei, L. Hao, J. Wenzhong, M. Zhiyu, L. Guihua and W. Xiaofeng: Int. J. Adv. Manuf. Technol. 85 (2016) 355-363.

74) G. Faraji, H.S. Kim and H.T. Kashi: Severe Plastic Deformation, ed. by G. Faraji, H.S. Kim and H.T. Kashi, (Elsevier, Amsterdam, 2018) pp. 165-186.

75) A. Babaei, G. Faraji, M. Mashhadi and M. Hamdi: Mater. Sci. Eng. A 558 (2012) 150-157.

76) A.P. Zhilyaev, S. Rodriguez, J. Calvo and J.M. Cabrera: Novel Method of Severe Plastic Deformation-Continuous Closed Die Forging: CP Aluminum Case Study, Defect and Diffusion Forum, (Trans Tech Publ, 2018) pp. 302-307.

77) V. Spuskanyuk, A. Spuskanyuk and V. Varyukhin: J. Mater. Process. Technol. 203 (2008) 305-309.

78) K. Topolski, W. Pachla and H. Garbacz: J. Mater. Sci. 48 (2013) 4543-4548.

79) F. Samadpour, G. Faraji, P. Babaie, S. Bewsher and M. Mohammadpour: Mater. Sci. Eng. A 718 (2018) 412-417.

80) F. Samadpour, G. Faraji, P. Babaie, S.R. Bewsher and M. Mohammadpour: Mater. Sci. Eng. A 718 (2018) 412-417.

81) N. Pardis, B. Talebanpour, R. Ebrahimi and S. Zomorodian: Mater. Sci. Eng. A 528 (2011) 7537-7540.

82) G. Faraji and M.M. Savarabadi: Apparatus and method for fabricating high strength long nanostructured tubes, US Patent App. 15/989,141, 2018.

83) A. Hohenwarter: Mater. Sci. Eng. A 626 (2015) 80-85.

84) M. Eskandarzade, A. Masoumi, G. Faraji, M. Mohammadpour and X.S. Yan: J. Alloys Compd. 695 (2017) 1539-1546

85) U. Chakkingal, A.B. Suriadi and P.F. Thomson: Scr. Mater. 39 (1998) 677-684.

86) U. Chakkingal, A.B. Suriadi and P.F. Thomson: Mater. Sci. Eng. A 266 (1999) 241-249.

87) J. Alkorta, M. Rombouts, J. De Messemaeker, L. Froyen and J. Gil Sevillano: Scr. Mater. 47 (2002) 13-18.

88) R.Z. Valiev and T.G. Langdon: Prog. Mater. Sci. 51 (2006) 881-981.

89) C.J. Luis Pérez, C. Berlanga and J. Pérez-Ilzarbe: J. Mater. Process. Technol. 143-144 (2003) 105-111.

90) A.A. Zisman, V.V. Rybin, S. Van Boxel, M. Seefeldt and B. Verlinden: Mater. Sci. Eng. A 427 (2006) 123-129.

91) S. Dobatkin, J. Zrnik and I. Mamuzić: Metallurgy 49 (2010) 343-347.

92) D. Green: J. Inst. Met. 100 (1972) 295-300.

93) C. Etherington: J. Eng. Ind. 96 (1974) 893-900.

94) G.J. Raab, R.Z. Valiev, T.C. Lowe and Y.T. Zhu: Mater. Sci. Eng. A 382 (2004) 30-34.
95) M. Eftekhari, G. Faraji, S. Nikbakht, R. Rashed, R. Sharifzadeh, R. Hildyard and M. Mohammadpour: Mater. Sci. Eng. A 703 (2017) 551-558.

96) Y.L. He, F. Gao, B.Y. Song, R. Fu, G.M. Wu, J. Li and L. Jiang: Mater. Sci. Forum 706-709 (2012) 1781-1786.

97) J.-C. Lee, H.-K. Seok, J.-H. Han and Y.-H. Chung: Mater. Res. Bull. 36 (2001) 997-1004.

98) C.Y. Nam, J.H. Han, Y.H. Chung and M.C. Shin: Mater. Sci. Eng. A 347 (2003) 253-257.

99) J.C. Lee, J.Y. Shu and J.P. Ahn: Metall. Mater. Trans. A 34 (2003) $625-632$.

100) J.-Y. Suh, J.-H. Han, K.-H. Oh and J.-C. Lee: Scr. Mater. 49 (2003) 185-190.

101) J.-W. Park, J.-W. Kim and Y.-H. Chung: Scr. Mater. 51 (2004) 181184.

102) A. Azimi, S. Tutunchilar, G. Faraji and M.B. Givi: Mater. Des. 42 (2012) 388-394.

103) J.-C. Lee, Y.-H. Chung, H.-K. Seok, J.-Y. Suh and J.-H. Han: Metall. Mater. Trans. A 33 (2002) 665-673.

104) J.C. Lee, H.K. Seok and J.Y. Suh: Acta Mater. 50 (2002) 4005-4019.

105) S.Y. Utsunomiya: J. Mater. Eng. Perform. 6 (1997) 319-325.

106) Y. Saito, H. Utsunomiya, H. Suzuki and T. Sakai: Scr. Mater. 42 (2000) 1139-1144

107) H. Utsunomiya, K. Hatsuda, T. Sakai and Y. Saito: Mater. Sci. Eng. A 372 (2004) 199-206.

108) H. Utsunomiya, Y. Saito, H. Suzuki and T. Sakai: Proc. Inst. Mech. Eng., B: J. Eng. Manuf. 215 (2001) 947-957.

109) H.H. Lee, J.I. Yoon and H.S. Kim: Scr. Mater. 146 (2018) 204-207.

110) C. Xu, S. Schroeder, P.B. Berbon and T.G. Langdon: Acta Mater. 58 (2010) 1379-1386.

111) Y. Huang and P.B. Prangnell: Scr. Mater. 56 (2007) 333-336.

112) R.C. Srinivasan, K. Prabir, B. Cherukuri, Q. Han, D. Swenson and P. Gros: Continuous Severe Plastic Deformation Processing of Aluminum Alloys, University of North Texas Libraries, Digital Library, digital.library.unt.edu; crediting UNT Libraries Government Documents Department, (2006).

113) M.Y.Y. Takayama, T. Tozawa, H. Kato, H. Watanabe and T. Izawa: Proc. fourth Intern. Conf. on Recrystallization and Related Phenomena (JIMIS10), (The Japan Institute of Metals, 1999) pp. 321326.

114) Y. Takayama, T. Miura, H. Kato and H. Watanabe: Mater. Trans. 45 (2004) 2826-2831.

115) H. Jin and D.J. Lloyd: Mater. Sci. Eng. A 399 (2005) 358-367.

116) S.H. Lee and D.N. Lee: Int. J. Mech. Sci. 43 (2001) 1997-2015.

117) H. Watanabe, T. Mukai and K. Ishikawa: J. Mater. Sci. 39 (2004) 1477-1480.

118) Y.H. Ji, J.J. Park and W.J. Kim: Mater. Sci. Eng. A 454(Suppl. C) (2007) 570-574.

119) Y.H. Ji and J.J. Park: Mater. Sci. Eng. A 499 (2009) 14-17.

120) T. Lee, C.H. Park, S.-Y. Lee, I.-H. Son, D.-L. Lee and C.S. Lee: Met. Mater. Int. 18 (2012) 391-396.

121) T. Mukai, H. Somekawa, T. Inoue and A. Singh: Scr. Mater. 62 (2010) $113-116$.

122) K. Topolski and H. Garbacz: Mater. Sci. Eng. A 739 (2019) 277-288.

123) P. Rostami: Trans. Indian Inst. Met. 71 (2018) 1083-1090.

124) A. Azushima, R. Kopp, A. Korhonen, D.Y. Yang, F. Micari, G.D. Lahoti, P. Groche, J. Yanagimoto, N. Tsuji, A. Rosochowski and A. Yanagida: CIRP Annals 57 (2008) 716-735.

125) K. Edalati and Z. Horita: J. Mater. Sci. 45 (2010) 4578-4582.

126) A. Hohenwarter and R. Pippan: Adv. Eng. Mater. 20 (2018) 1800050.

127) J. Huang, Y. Zhu, H. Jiang and T. Lowe: Acta Mater. 49 (2001) 14971505.

128) W. Głuchowski, J. Stobrawa and Z. Rdzawski: Archives Mater. Sci. Eng. 47(2) (2011) 103-109.

129) J.W. Lee and J.J. Park: J. Mater. Process. Technol. 130 (2002) 208213.

130) Y. Saito, H. Utsunomiya, N. Tsuji and T. Sakai: Acta Mater. 47 (1999) 579-583.

131) Y. Murata, I. Nakaya and M. Morinaga: Mater. Trans. 49 (2008) 2023.

132) N. Tsuji, K. Shiotsuki and Y. Saito: Mater. Trans., JIM 40 (1999) 765- 
771.

133) M.R. Toroghinejad, R. Jamaati, J. Dutkiewicz and J.A. Szpunar Mater. Des. 51 (2013) 274-279.

134) A. Mirsepasi, M. Nili-Ahmadabadi, M. Habibi-Parsa, H. GhasemiNanesa and A.F. Dizaji: Mater. Sci. Eng. A 551 (2012) 32-39.

135) K. Nakamura, K. Neishi, K. Kaneko, M. Nakagaki and Z. Horita Mater. Trans. 45 (2004) 3338-3342.

136) W. Bochniak, K. Marszowski and A. Korbel: J. Mater. Process. Technol. 169 (2005) 44-53.

137) A. Korbel and W. Bochniak: Scr. Mater. 51 (2004) 755-759.

138) A. Korbel, W. Bochniak, P. Ostachowski and L. Błaż: Metall. Mater. Trans. A 42 (2011) 2881-2897.

139) A. Gusak, M. Danielewski, A. Korbel, M. Bochniak and N. Storozhuk: J. Appl. Phys. 115 (2014) 034905.

$140)$ N. Pardis, C. Chen, M. Shahbaz, R. Ebrahimi and L.S. Toth: Mater Sci. Eng. A 613 (2014) 357-364.

141) S. Hwang, Y. Jin, I. Son, K. Rhee, D. Lee and Y.-T. Im: Int. J. Mech. Sci. 53 (2011) 479-484.

142) K. Edalati, K. Imamura, T. Kiss and Z. Horita: Mater. Trans. 53 (2012) 123-127.
143) H.S. Kim: Mater. Trans. 42 (2001) 536-538.

144) C. Xu, K. Xia and T.G. Langdon: Acta Mater. 55 (2007) 2351-2360.

145) F. Djavanroodi and M. Ebrahimi: Mater. Sci. Eng. A 527 (2010) $1230-1235$.

146) G.E. Dieter, H.A. Kuhn and S.L. Semiatin: Handbook of Workability and Process Design, (ASM International, Ohio, 2003).

147) J. Skiba, W. Pachla, A. Mazur, S. Przybysz, M. Kulczyk, M. Przybysz and M. Wróblewska: J. Mater. Process. Technol. 214 (2014) 67-74.

148) R. Pippan, S. Scheriau, A. Taylor, M. Hafok, A. Hohenwarter and A. Bachmaier: Annu. Rev. Mater. Res. 40 (2010) 319-343.

149) S. Lu, Q.-M. Hu, E.K. Delczeg-Czirjak, B. Johansson and L. Vitos: Acta Mater. 60 (2012) 4506-4513.

150) H. Utsunomiya, K. Hatsuda, T. Sakai and Y. Saito: Mater. Sci. Eng. A 372 (2004) 199-206.

151) F. Samadpour, G. Faraji, P. Babaie, S. Bewsher and M. Mohammadpour: Mater. Sci. Eng. A 718 (2018) 412-417.

152) A. Hohenwarter and R. Pippan: Adv. Eng. Mater. 20 (2018) 1800050.

153) A. Zisman, V. Rybin, S. Van Boxel, M. Seefeldt and B. Verlinden: Mater. Sci. Eng. A 427 (2006) 123-129. 